\title{
The three-point bending test of fiber-reinforced composite root canal posts
}

\author{
Michał Biały ${ }^{1, A, B, D, F}$, Agnieszka Szust ${ }^{2, C, E, F}$, Piotr Napadłek ${ }^{1, B, E, F}$, Maciej Dobrzyński, ${ }^{3, B, E, F}$, Włodzimierz Więckiewicz ${ }^{1, A, E, F}$ \\ ${ }^{1}$ Department of Dental Prosthetics, Wroclaw Medical University, Poland \\ 2 Faculty of Mechanical Engineering, Wroclaw University of Science and Technology, Poland \\ ${ }^{3}$ Department of Conservative Dentistry and Pedodontics, Wroclaw Medical University, Poland \\ A - research concept and design; B - collection and/or assembly of data; $\mathrm{C}$ - data analysis and interpretation; \\ $\mathrm{D}$ - writing the article; $\mathrm{E}$ - critical revision of the article; $\mathrm{F}$ - final approval of the article
}

\section{Address for correspondence}

Michał Biały

E-mail: dentystamichalbialy@gmail.com

Funding sources

This research was financially supported

by the Ministry of Health subvention according

to the number of STM.B020.20.035 from

the IT Simple system of Wroclaw Medical Univeristy, Poland

Conflict of interest

None declared

Received on March 28, 2020

Reviewed on May 25, 2020

Accepted on July 16, 2020

Published online on October 1, 2020

Cite as

Biały M, Szust A, Napadłek P, Dobrzyński M, Więckiewicz W. The three-point bending test of fiber-reinforced composite root canal posts. Adv Clin Exp Med. 2020;29(9):1111-1116. doi:10.17219/acem/125426

DOI

10.17219/acem/125426

\section{Copyright}

Copyright by Author(s)

This is an article distributed under the terms of the

Creative Commons Attribution 3.0 Unported (CC BY 3.0)

(https://creativecommons.org/licenses/by/3.0/)

\section{Abstract}

Background. The primary reason for using a post is to retain the core with the objective to restore the missing coronal tooth structure. To achieve optimum results, the materials that are used to restore endodontically treated teeth should have physical and mechanical properties that are similar to that of dentin.

Objectives. To characterize the strength parameters of fiber-reinforced composite (FRC) posts with the application of a three-point test. The mean fracture load, flexural strength and flexural modulus were taken into consideration.

Material and methods. For the three-point strength tests, 5 kinds of fiberglass root-posts were used: GC Fiber Post (GC America, Alsip, USA), Mirafit White (Hager Werken, Duisburg, Germany), Innopost (InnoTech, Verona, Italy), Rebilda Post (Voco, Cuxhaven, Germany), and EverStick Post (GC Europe, Leuven, Belgium). For each system, 15 FRC posts were tested. All posts had the same diameter, length and shape. The three-point test was carried out in accordance with ISO 10477:2004, using the Instron-5944 testing machine (Instron, Norwood, USA). The test was carried out until the sample was broken.

Results. The highest force values (67.6 N) were recorded for the GC posts, and the lowest force required to break the sample $(29.6 \mathrm{~N})$ was noted for the EverStick Posts. In the case of bending strength, the highest values were also recorded for $\mathrm{GC}$ posts (912.4 MPa). Low bending strengths were obtained for the Mirafit White posts (537.2 MPa); however, the EverStick Posts were the weakest (436.2 MPa). Rebilda posts showed the highest modulus of elasticity $-31.1 \mathrm{GPa}$. The lowest values of the elastic modulus were registered for EverStick Posts - $12.5 \mathrm{GPa}$.

Conclusions. There were statistically significant differences in fracture loads, flexural strengths and flexural modulus of the FRC-post systems tested. Individually polymerized FRC material showed lower flexural properties than compared prefabricated FRC posts.

Key words: three-point bending test, flexural modulus, flexural strength, fiber-reinforced composite post, individually formed post 


\section{Introduction}

Posts provide retention for dental materials while the missing coronal tooth structure is being restored. They do not strengthen the tooth. ${ }^{1,2}$ To achieve optimum results, the materials that are used for restoration of endodontically treated teeth should have physical and mechanical properties similar to dentin. ${ }^{3}$ There is a difference of opinion whether a post should have an elastic modulus close to dentin ${ }^{4-6}$ or whether it should be more rigid. ${ }^{7,8}$ Posts can be classified based on the elastic modulus, with metallic posts (prefabricated or cast metal posts), ceramic posts and carbon fiber posts presenting high values, and glass fiber posts presenting low elastic modulus. ${ }^{9,10}$ Prefabricated and cast metal posts are rigid in nature. ${ }^{11}$ The rigidity may pose a risk for root fracture. One of the major reasons that motivated researchers to find alternative solutions to metal posts was to prevent root fracture, which was the main cause of failure with this type of restoration. The biomechanical properties of fiber-reinforced composite (FRC) posts have been reported to be similar to that of dentin. ${ }^{12-14}$ Clinical prospective and retrospective studies on the use of fiber posts have reported encouraging results. ${ }^{15-19}$

The first FRC-posts were made of carbon/graphite fibers due to their good mechanical properties. However, they are black in color and thus lack cosmetic qualities. Instead posts made of glass or silica fibers are white or translucent and can be used in situations of higher cosmetic demand. ${ }^{12,20}$

Dental market offers prefabricated and individually formed glass fiber posts. However, prefabricated FRC posts have limitations in their properties, such as poor anatomical fit to the canal. They require preparation of the root canal to fit the shape of the post, which causes loss of dentin and makes the root more vulnerable to root fracture. ${ }^{21}$ This emphasizes the importance of trying to preserve the original anatomy of the root canal and minimizing dentin loss throughout the endo-restorative treatment. ${ }^{22,23}$ Large root preparation can be avoided by using individually formed FRC posts. ${ }^{12,24-26}$ An individually formed FRC post can be polymerized in situ in the root canal, thus precisely following the shape of the canal. ${ }^{27}$ The manufacturer's recommendation has been to light-polymerize in 2 phases; first, a short curing is carried out when the post material is placed in the root canal to copy the anatomical shape of the canal. After that the final curing is carried out after removing the post from the canal to ensure complete curing also at the apical parts of the post.

The polymer matrix of individually formed FRC post material consists of both linear and cross-linked phases, which is called semi-interpenetrating polymer network (IPN). ${ }^{21}$ This matrix also allows the formation of secondary IPN bonding based on interdiffusion of the resin systems of post and luting cement. The IPN system improves adhesion to composite and increases flexural strength and fatigue strength through the reduction of crack initiation.
Polymer matrix of the FRC post used in the present study is composed of cross-linking monomer system of bisphenol-A-dimethacrylate (Bis-GMA) and linear polymers of polymethyl methacrylate (PMMA) which structurally form semi-interpenetrating polymer networks (semiIPN). ${ }^{21}$ Resiliency of semi-IPN based composites is higher and modulus of elasticity is lower compared to polymer made of crosslinking monomers only. ${ }^{28,29}$

The aim of this study is to:

1) characterize the strength parameters of FRC posts with the application of a three-point test. The mean fracture load, flexural strength and flexural modulus were be taken into consideration.

2) compare the properties of prefabricated FRC posts with custom-made FRC posts in the form of a tape, which achieve full stiffness after the exposure to a polymerization lamp.

3) establish which FRC posts are the most suitable for clinical use.

\section{Material and methods}

For this study, 5 different types of endodontic post were selected:

- group 1: GC Fiber Post (GC America, Alsip, USA);

- group 2: Mirafit White (Hager Werken, Duisburg, Germany);

- group 3: Innopost (InnoTech, Verona, Italy);

- group 4: Rebilda Post (Voco, Cuxhaven, Germany); and

- group 5: EverStick (GC Europe, Leuven, Belgium).

Seventy-five endodontic posts, 15 for each group, were tested. All fiber posts were $1.2 \mathrm{~mm}$ in diameter, $20 \mathrm{~mm}$ in length and had a cylindrical shape with a tapered end. In order to reduce the influence of the conical end of the posts, a $10 \mathrm{~mm}$ parallel part of the post was used for the tests.

The EverStick fiber material containing silanized E-glass fibers in light-polymerizable dimethacrylate - polymethylmethacrylate matrix was made into a cylindrical shaped specimen with a diameter of $1.2 \mathrm{~mm}$. EverStick Posts were treated according to the manufacturers' instructions. Tweezers were used to take the post out from the silicone. The length and suitability were checked using electronic caliper. The specimens were polymerized in a light curing lamp for $60 \mathrm{~s}$. A light-polymerizing device (Elipar S10; 3M Espe, Maplewood, USA) with halogen lamp radiating blue light (wavelength 430-480 $\mathrm{nm}$ ) and with an intensity of $1200 \mathrm{~mW} / \mathrm{cm}^{2}$ was used.

The three-point bending test according to the ISO 10477 standard (span $10.0 \mathrm{~mm}$, crosshead speed $1.0 \mathrm{~mm} /$ min, cross-sectional diameter of loading tip $2 \mathrm{~mm}$ ) was used to measure the flexural strength and modulus of FRC post specimens. All posts were tested with the material testing machine Instron-5944 (Instron, Norwood, USA). The test was carried out until the sample was broken 


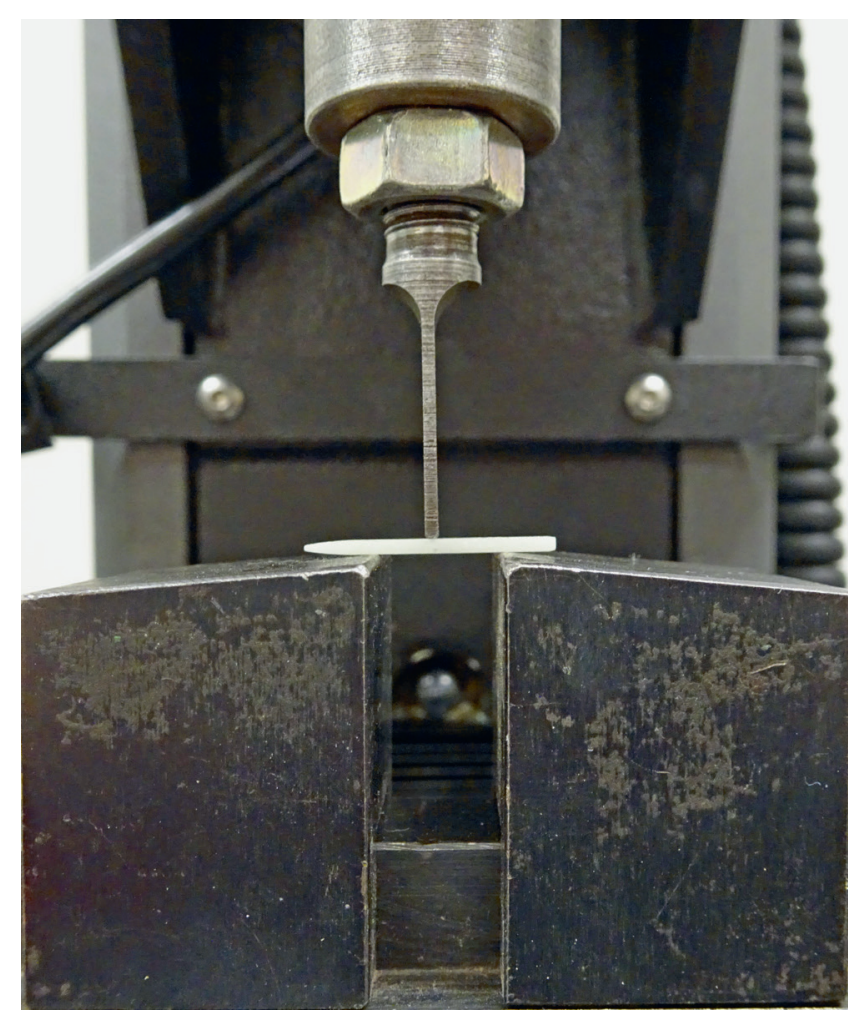

Fig. 1. The post during three-point bending test

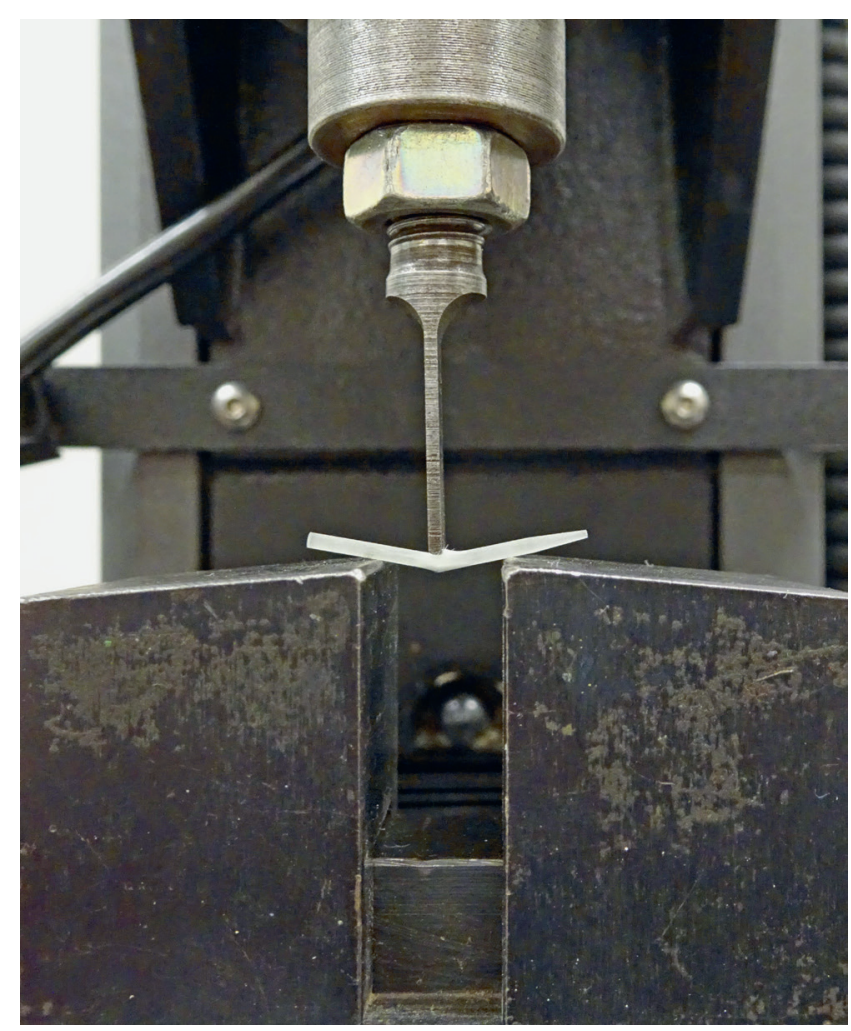

Fig. 2. The broken post after three-point bedning test

(Fig. 1,2). All the tests were carried out in temperature about $22^{\circ} \mathrm{C}$. Fracture load of post was measured. Flexural strength $(\sigma)$ and flexural modulus $(E)$ were calculated from the formula:

$$
\begin{gathered}
\sigma=8 \mathrm{~F}_{\max } \mathrm{L} / \pi \mathrm{d}^{3}[\mathrm{MPa}] \\
\mathrm{E}=4 \mathrm{~F}_{\max } \mathrm{L}^{3} /\left(\mathrm{D} 3 \pi \mathrm{d}^{4}\right)[\mathrm{GPa}],
\end{gathered}
$$

where: $F_{\text {max }}$ is the maximum load point of the load-deflection curve $[\mathrm{N}]$, $\mathrm{L}$ is the distance between the support rollers $(10.0 \mathrm{~mm}), \mathrm{d}$ is the diameter of the specimens $[\mathrm{mm}]$, and $\mathrm{D}$ is deflection $[\mathrm{mm}]$ at Fmax ${ }^{[16]}$ at a point in the straightline portion of the trace.

The differences between specimens were evaluated using Kruskal-Wallis nonparametric analysis of variance (ANOVA) and the median test. The probability level was set at 0.05 .

\section{Results}

In the conducted three-point test, the values of maximum forces that caused damage to the FRC post were observed (Table 1). The ANOVA revealed significant differences ( $\mathrm{p}=0.05)$ in fracture loads, flexural strengths and flexural modulus of the FRC-post systems tested. The highest force values $(67.6 \mathrm{~N})$ were recorded for the GC Fiber Posts and the lowest force required to break the sample $(29.6 \mathrm{~N})$ was noted for the EverStick Posts (Fig. 3). In the case of bending strength, the highest values were also recorded for GC Fiber Posts - 912.4 MPa (Fig. 4). Low bending strengths were obtained for the Mirafit White posts (537.2 MPa); however, the EverStick Posts were the weakest (436.2 MPa). The elastic modulus was also calculated. Rebilda posts showed the highest modulus of elasticity - 31.1 GPa (Fig. 5). Slightly lower modulus was recorded for GC Fiber Posts - 30.9 GPa; however, the lowest values of the elastic modulus were registered for Mirafit White posts and EverStick Posts - 21.7 GPa and 12.5 GPa, respectively. The elastic module of EverStick Posts proved to be lower than the dentine elasticity modulus, which was $17.5 \pm 3.8 \mathrm{GPa}$.

\begin{tabular}{|c|c|c|c|c|}
\hline Group & $\begin{array}{l}\text { Posts } \\
\text { type }\end{array}$ & $\begin{array}{l}\text { Fracture } \\
\text { load [N] }\end{array}$ & $\begin{array}{c}\text { Flexural } \\
\text { strength [MPa] }\end{array}$ & $\begin{array}{c}\text { Flexural } \\
\text { modulus [GPa] }\end{array}$ \\
\hline Group 1 & $\begin{array}{l}\text { GC Fiber } \\
\text { Post }\end{array}$ & $67.6 \pm 3.9$ & $992.4 \pm 58.3$ & $30.9 \pm 0.9$ \\
\hline Group 2 & $\begin{array}{l}\text { Mirafit } \\
\text { White }\end{array}$ & $36.5 \pm 3.2$ & $537.2 \pm 47.3$ & $21.7 \pm 0.9$ \\
\hline Group 3 & Innopost & $52.5 \pm 4.3$ & $773.5 \pm 59.6$ & $23.5 \pm 1.6$ \\
\hline Group 4 & $\begin{array}{l}\text { Rebilda } \\
\text { Post }\end{array}$ & $65.3 \pm 3.3$ & $962.1 \pm 48.6$ & $31.1 \pm 1.1$ \\
\hline Group 5 & $\begin{array}{l}\text { EverStick } \\
\text { Post }\end{array}$ & $29.6 \pm 5.1$ & $436.2 \pm 75.9$ & $12.5 \pm 2.7$ \\
\hline
\end{tabular}

Table 1. The fracture load and flexural properties

\section{Discussion}

Many studies investigating the flexural properties of root canal posts have been published, reporting results that varied greatly. $2,12,30-32$ The flexural modulus parameter 


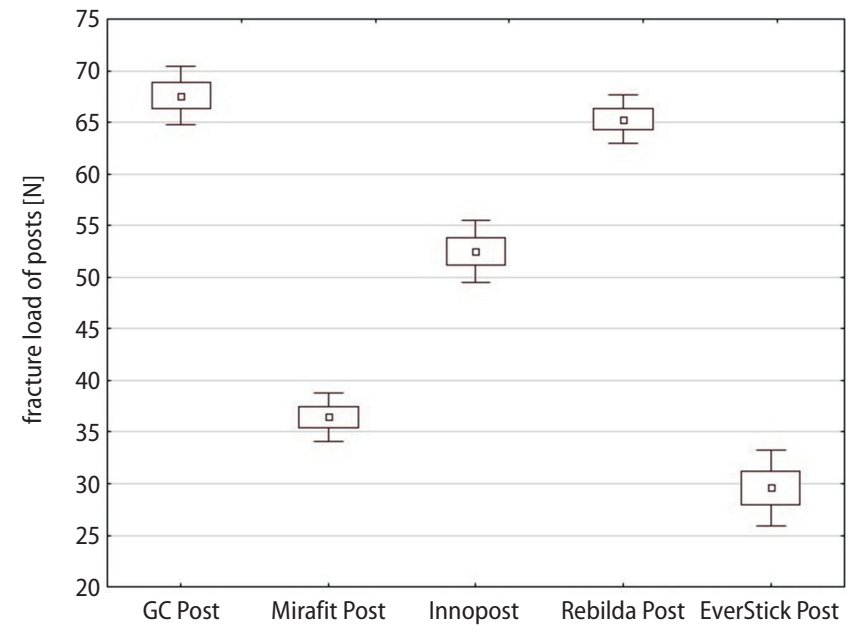

Fig. 3. The fracture load of posts

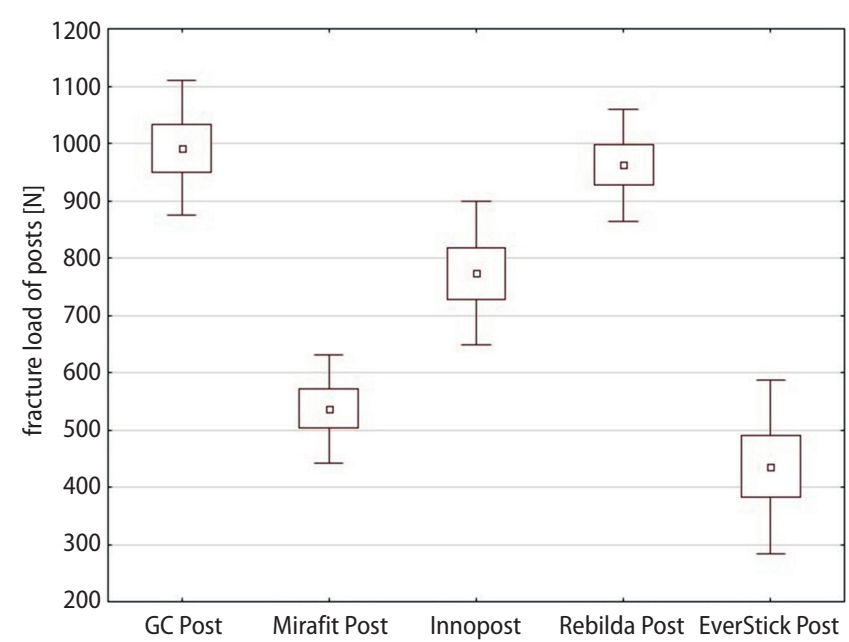

Fig. 4. The flexural strength of posts

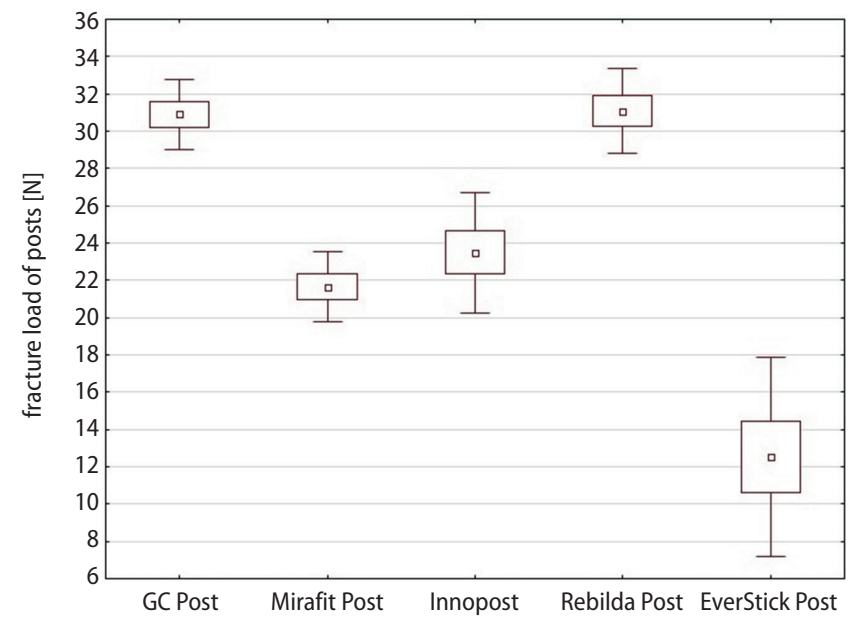

Fig. 5. The flexural modulus of posts

defines the flexibility of a sample and higher values indicate more stiffness, while lower values indicate more flexibility. The flexural modulus is calculated by taking into account the elastic behavior of a sample within a load range that will not cause plastic deformation. The flexural strength parameter determines the resistance to fracture. ${ }^{2}$ Higher values indicate that a sample is more resistant to fracture, whereas lower values indicate that it is less so. The flexural strength is determined by the highest load a sample can withstand and depends on the specimen configuration.

In this study, the posts were tested dry at room temperature and even though the authors agree with published reports that humidity can alter the mechanical properties of fiber posts, ${ }^{2,30,33,34}$ it has been demonstrated that within the tooth, the behavior of posts is comparable to that of dry posts. ${ }^{14,32}$ Lassila et al. revealed that thermocycling for FRC posts had a significant effect on the fracture load and flexural strength. ${ }^{12}$ In general, thermocycling decreased the flexural modulus of the tested FRC posts by about $10 \%$. Strength and fracture load decreased by about $18 \%$. Thermocycling slightly decreased the bond strength at the fiber post-core interface. ${ }^{35}$

The EverStick Posts were polymerized in a light-curing lamp (Elipar) for $60 \mathrm{~s}$. Cacciafesta et al. claimed that oven post-curing does not increase the flexural strength values of FRC EverStick Posts compared with conventional hand light-curing. ${ }^{36}$

In the case of prefabricated conventional FRC posts, the location of the post in the center of the root - in the neutral axis of tubular structure - is not optimal to provide effective reinforcing effect by the fibers of the post for the root-core-crown system. ${ }^{21}$ In addition, by using the prefabricated FRC posts, the free space of the coronal root canal opening is filled only with weaker particulate filler composite resin cement. In the individually formed, also called custom-made, FRC posts, the fiber volume at the coronal part of the root canal is high and it fills the entire available root canal space. This increases the stiffness and strength of that part of the post and forms a strong support for the core. By considering the mechanics of tubular structure of a tooth and post system, the individually formed posts also provide fiber location closer to the outermost surface of the root, where the high functional stresses are located. Stress distribution in dentin is related to bone height level. ${ }^{37}$ Singh et al. assessed that the stress in the dentin, post and the cement was much higher in the tooth with the alveolar bone height of $4 \mathrm{~mm}$ from cementoenamel junction (CEJ) compared to the tooth with bone support of $2 \mathrm{~mm}$ alveolar bone height from the CEJ. ${ }^{37}$

Lassila et al. claimed that EverStick in their studies presented the highest flexural strength values. ${ }^{12}$ Their study investigated the flexural properties of different types of FRC posts (Snowpost, Carbopost, Parapost, C-post, Glassix, and Carbonite) and compared those values with a FRC material for dental applications (EverStick). A threepoint bending test (span: $10 \mathrm{~mm}$ ) was used to measure the flexural strength and modulus of FRC post specimens. The highest flexural strength was obtained with the control material (EverStick). They claimed that this unexpected finding could be explained by the optimization 
of the polymer matrix and fiber properties to function as a composite material. More precisely, the difference in the polymer matrix of EverStick compared to the matrices of other tested FRCs is based on the existence of poly(methyl methacrylate) (PMMA) chains in the crosslinked polymer matrix. The PMMA chains with a molecular weight of $220 \mathrm{KD}$ plasticize the cross-linked BisGMA-based matrix of the EverStick FRC and reduce stress formation in the fiber-matrix interface during deflection. This may be assumed to contribute to the higher strength of EverStick FRC material. ${ }^{38}$

A different study examined the flexural strength of 2 different fiber post-resin cement systems and the results showed significant differences between the flexural strength of the prefabricated GC Fiber Posts and the individually formed EverStick Posts. ${ }^{39}$ A four-point bend test was carried out till failure on all groups. The highest flexural strengths were found for the GC Fiber Posts without silane pretreatment and the second-highest flexural strengths were found for the GC Fiber Posts with silane pretreatment, both of which were higher than the flexural strengths of the EverStick Posts.

Cagidiaco et al. assessed whether the amount of residual coronal dentin and the placement of a prefabricated (DT Light Post) or a individually formed (EverStick Post) have a significant influence on the three-year survival of endodontically treated premolars. ${ }^{40}$ Teeth restored with prefabricated DT Light Posts had a three-year survival rate higher (90.9\%) than those restored with individually formed EverStick Posts (76.7\%).

\section{Conclusions}

The following conclusions can be drawn from the study:

1. There were statistically significant differences in fracture loads, flexural strengths and flexural modulus of the FRC-post systems tested.

2. Prefabricated FRC posts exhibit favorable mechanical properties in comparison to individually polymerized FRC. Therefore, their application may result in enhanced clinical performance of endodontically treated teeth.

\section{ORCID iDs}

Michał Biały (1) https://orcid.org/0000-0002-7999-046X Agnieszka Szust (1) https://orcid.org/0000-0002-6448-6703 Piotr Napadłek (1) https://orcid.org/0000-0001-8464-2905 Maciej Dobrzyński (1) https://orcid.org/0000-0003-2368-1534 Włodzimierz Więckiewicz (1) https://orcid.org/0000-0002-8116-7229

\section{References}

1. Saupe WA, Gluskin AH, Radke Jr RA. A comparative study of fracture resistance between morphologic dowel and cores and a resin-reinforced dowel system in the intraradicular restoration of structurally compromised roots. Quintessence Int. 1996;27(7):483-491.

2. Plotino G, Grande NM, Bedini R, Pameijer CH, Somma F. Flexural properties of endodontic posts and human root dentin. Dent Mater. 2007; 23(9):1129-1135.
3. Fernandes AS, Shetty $S$, Coutinho I. Factors determining post selection: A literature review. J Prosthet Dent. 2003;90(6):556-562.

4. Stewardson DA, Shortall AS, Marquis PM, Lumley PJ. The flexural properties of endodontic post materials. Dent Mater. 2010;26(8): 730-736.

5. Ferrari M, Scotti R. Fiber Posts. Characteristics and Clinical Applications. Milan, Italy: Masson; 2002.

6. Prisco D, De Santis R, Mollica F, Ambrosio L, Rengo S, Nicolais L. Fiber post adhesion to resin luting cements in the restoration of endodontically treated teeth. Oper Dent. 2003;28(5):515-521.

7. Manning KE, Yu DC, Yu HC, Kwan EW. Factors to consider for predictable post and core build-ups of endodontically treated teeth. Part II. Clinical application of basic concepts. J Can Dent Assoc. 1995;61(8): 696-707.

8. Asmussen E, Peutzfeldt A, Sahafi A. Finite element analysis of stresses in endodontically treated, dowel-restored teeth. J Prosthet Dent. 2005;94(4):321-329.

9. Sarkis-Onofre R, Amaral Pinheiro H, Poletto-Neto V, Dalmolin Bergoli C, Cenci MS, Pereira-Cenci T. Randomized controlled trial comparing glass fiber posts and cast metal posts. J Dent. 2020;4:14.

10. Soares CJ, Valdivia AD, Silva GR, Santana FR, Menezes S. Longitudinal clinical evaluation of post systems: A literature review. Braz Dent J. 2012;23(2):135-140.

11. Ulgey M, Zan R, Hubbezoglu I, Gorler O, Uysalcan G, Cotur F. Effect of different laser types on bonding strength of CAD/CAM-customized zirconia post to root canal dentin: An experimental study. Lasers Med Sci. 2020;35(6):1385-1392.

12. Lassila LVJ, Tanner J, Le Bell AM, Narva K, Vallittu PK. Flexural properties of fiber reinforced root canal posts. Dent Mater. 2004;20(1):29-36.

13. Drummond JL, Bapna MS. Static and cyclic loading of fiber-reinforced dental resin. Dent Mater. 2003;19(3):226-231.

14. Mannocci F, Sherriff M, Watson TF. Three-point bending test of fiber posts. J Endod. 2001;27(12):758-761.

15. Dallari A, Rovatti L. Six years of in vitro/in vivo experience with Composipost. Compend Contin Educ Dent Suppl. 1996;20:S57-S63.

16. Fredriksson M, Astback J, Pamenius M, Arvidson K. A retrospective study of 236 patients with teeth restored by carbon fiber-reinforced epoxy resin posts. J Prosthet Dent. 1998;80(2):151-157.

17. Ferrari M, Vichi A, Mannocci F, Mason PM. Retrospective study of the clinical performance of fiber posts. Am J Dent. 2000;13(Spec No): 9B-13B.

18. Ferrari M, Vichi A, Garcia-Godoy F. Clinical evaluation of fiber-reinforced epoxy resin posts and cast post and cores. Am J Dent. 2000; 13(Spec No):15B-18B.

19. Glazer B. Restoration of endodontically treated teeth with carbon fibre posts: A prospective study. J Can Dent Assoc. 2000;66(11):613-618.

20. Doshi P, Kanaparthy A, Kanaparthy R, Parikh DS. A comparative analysis of fracture resistance and mode of failure of endodontically treated teeth restored using different fiber posts: An in vitro study. J Contemp Dent Pract. 2019;20(10):1195-1199.

21. Makarewicz D, Le Bell-Rönnlöf AM, Lassila LVJ, Vallittu PK. Effect of cementation technique of individually formed fiber-reinforced composite post on bond strength and microleakage. Open Dent J. 2013;7:68-75.

22. Fráter M, Forster A, Jantyik Á, Braunitzer G, Nagy K, Grandini S. In vitro fracture resistance of premolar teeth restored with fibrereinforced composite posts using a single or a multi-post technique. Aust Endod J. 2017;43(1):16-22.

23. Zicari F, Van Meerbeek B, Scotti R, Naert I. Effect of fibre post length and adhesive strategy on fracture resistance of endodontically treated teeth after fatigue loading. J Dent. 2012;40(4):312-321.

24. Peroz I, Blankenstein F, Lange K-P, Naumann M. Restoring endodontically treated teeth with posts and cores: A review. Quintessence Int. 2005;36(9):737-746.

25. Bitter K, Noetzel F, Neumann K, Kielbassa AM. Effect of silanization on bond strengths of fiber posts to various resin cements. Quintessence Int. 2007;38(2):121-128.

26. Le Bell-Rönnlöf A-M, Lassila LVJ, Kangasniemi I, Vallittu PK. Loadbearing capacity of human incisor restored with various fiber-reinforced composite posts. Dent Mater. 2011;27(6):e107-e115.

27. Le Bell A-M, Tanner J, Lassila LVJ, Kangasniemi I, Vallittu PK. Depth of light-initiated polymerization of glass fiber reinforced composite in a simulated root canal. Int J Prosthodont. 2003;16(4):403-408. 
28. Bouillaguet S, Schutt A, Alander P. Hydrothermal and mechanical stresses degarde fiber-matrix interfacial bond strength in dental fiber-reinforced composites. J Biomed Mater Res Part B Appl Biomater. 2006;76(1):98-105.

29. Pastila P, Lassila LVJ, Jokinen M, Vuorinen J, Vallittu PK, Mäntylä T. Effect of short-term water storage on the elastic properties of some dental restorative materials: An ultrasound spectroscopy study. Dent Mater. 2007;23(7):878-884.

30. Torbjorner A, Karlsson S, Syverud M, Hensten-Pettersen A. Carbon fiber reinforced root canal posts: Mechanical and citotoxic properties. Eur J Oral Sci. 1996;104(5-6):605-611.

31. Purton DG, Payne JA. Comparison of carbon fiber and stainless steel root canal posts. Quintessence Int. 1996;27(2):93-97.

32. Asmussen E, Peutzfeldt A, Heitmann T. Stiffness elastic limit, and strength of newer types of endodontic posts. J Dent. 1999;27(4):275-278.

33. Grant TS, Bradley WL. In situ observations in SEM of degradation of graphite/epoxy composite materials due to seawater immersion. J Compos Mater. 1995;29(7):852-867.

34. Lee MC, Peppas NA. Models of misture transport and misture-induced stresses in epoxy composites. J Compos Mater. 1993;27(12):1146-1171.
35. Hashemikamangar SS, Hasanitabatabaee M, Kalantari S, Gholampourdehaky M, Ranjbaromrani L, Ebrahimi H. Bond strength of fiber posts to composite core: Effect of surface treatment with Er,Cr:YSGG laser and thermocycling. J Lasers Med Sci. 2018;9(1):36-42.

36. Cacciafesta V, Sfondrini MF, Lena A, Scribante A, Vallittu PK, Lassila LV. Flexural strengths of fiber-reinforced composites polymerized with conventional light-curing and additional postcuring. Am J Orthod Dentofacial Orthop. 2007;132(4):524-527.

37. Singh SV, Gupta S, Sharma D, Pandit N, Nangom A, Satija H. Stress distribution of posts on the endodontically treated teeth with and without bone height augmentation: A three-dimensional finite element analysis. J Conserv Dent. 2015;18(3):196-199.

38. Vallittu PK. The Second International Symposium on Fiber-Reinforced Plastics in Dentistry. Turku, Finland: University of Turku. 2002:2-28.

39. Davis $P$, Melo LSD, Foxton RM, et al. Flexural strength of glass fibrereinforced posts bonded to dual-cure composite resin cements. Eur J Oral Sci. 2010;118(2):197-201.

40. Cagidiaco MC, Garcia-Godoy F, Vichi A, Grandini S, Goracci C, Ferrari M. Placement of fiber-prefabricated or custom-made posts affects the 3-year survival of endodontically treated premolars. Am J Dent. 2008;21(3):179-184. 